\title{
O cinema de Frank Capra e a tradição romântica
}

\section{The Capra's cinema and the romantic tradition}

Leonardo de Atayde Pereira ${ }^{1}$

\section{Resumo}

Os filmes de Frank Capra, principalmente aqueles produzidos nas décadas de 1930 e 1940, mais do que mero entretenimento para as massas, conseguiram traduzir uma série de temas importantes para o ideário norte-americano, como o de self made man, e da importância da integração do indivíduo frente ao coletivo. Dessa forma, Capra assumiu um papel de destaque diante da política do New Deal, de Franklin Delano Roosevelt, e seu cinema ganhou a missão de atuar como instrumento de propaganda política. Frank Capra conseguiu dialogar, mesmo que indiretamente, com uma longa tradição intelectual norte-americana, que pensou os problemas da nação a partir de uma ótica social e está integrada a uma visão de mundo romântica. Dentre a produção de Capra, o famoso "It's a wonderful life" ("A Felicidade não se Compra") é um dos que mais oferece possibilidades comparativas com temas oriundos da tradição transcendentalista e do realismo "poético" de John Steinbeck.

Palavras-chave: Frank Capra. Romantismo. Literatura norte-americana. Cinema.

\begin{abstract}
Frank Capra's films, mainly the ones produced in the 30's and 40's, are more than simple entertainment to the general public; they translated a series of relevant subjects to the American Ideology, as the self made man and the importance of the integration of the individual in contradiction of the collective. Thus, Capra has incorporated a highlighted role face of the political Franklin Delano Roosevelt "New Deal" and his cinema has gained a mission as a tool of political propaganda. Frank Capra managed to interact, although indirectly, to an old American intellectual tradition which has thought of the nation's problems from the social view and integrated to a romantic vision of the world. Among Capra's production, the famous "It's a wonderful life" is one of his works, which offers more comparative possibilities with subjects derived from the transcendentalist tradition and from John Steinbeck's "poetic" realism.
\end{abstract}

Keywords: Frank Capra. Romanticism. American Literature. Cinema.

\section{Introdução}

O presente trabalho tem como objetivo central apontar a presença de uma particular visão de mundo romântica ${ }^{2}$ no filme de Frank Capra - "A Felicidade não se

\footnotetext{
1 Universidade de São Paulo (USP). Doutorando em Estudos Comparados de Literaturas de Língua Portuguesa. E-mail: leonardopereira81@hotmail.com.
} 
compra". Para isso, foi levada em consideração a presença das temáticas românticas dentro de um movimento de apropriação histórica, ocorrida na cultura norte-americana. Essa apropriação de valores e heranças temáticas, muitas vezes, se deu de forma indireta e por intermédio de uma série de fatores, como nos momentos de construção de um ideário de nacionalidade para o povo norteamericano, em que muitos elementos do imaginário romântico europeu foram ressignificados.

Antes de iniciar a análise do filme, de seu roteiro e de seus personagens, e de suas possibilidades de aproximações teóricas oferecidas, torna-se necessário uma elucidação do que foi, em linhas gerais, o movimento romântico e quais elementos mais significativos fizeram parte do seu cabedal crítico.

Historicamente, o Romantismo é situado por diversos autores como movimento ou fenômeno decorrente de mudanças estruturais de ordem econômica, política e social, causadas pelo impacto das Revoluções Industrial e Francesa. Para autores críticos como Hobsbawm, Falbel e Saliba, uma perspectiva diferente de encarar a vida e o conhecimento humano surge de uma nova sensibilidade, que vai se formando do final do século XVIII até a metade do século XIX.

O cotidiano do europeu, constituído por antigas e tradicionais relações sociais, sofrera alterações radicais com o desenvolvimento econômico industrial, que passou a ser impulsionado, gradativamente, por uma produção em larga escala e maximização dos lucros nas relações comerciais. Essas mudanças causaram interferências nas relações do homem com o seu trabalho e transformaram o trabalhador numa mera engrenagem dentro da política econômica do capitalismo industrial.

Em meio à grande expansão econômica, ao súbito enriquecimento de uma minoria, da desabalada corrida dos inventos e inovações no setor tecnológico, e à crença na prosperidade e progresso humanos, surgiram graves problemas de ordem social em relação às massas de trabalhadores que este processo mobilizava e proletarizava [...]. A precariedade das instalações industriais, a falta de segurança, as péssimas condições higiênicas dos locais onde mulheres e crianças constituíam a mão-de-obra ao lado de homens, respirando o ar contaminado das minas, das oficinas

2 Conceito formulado por Lowy e Sayre na sua interpretação do movimento romântico e de seus significados, e presente de maneira mais abrangente e profunda, no livro "Revolta e Melancolia - O Romantismo na contramão da modernidade". 
mal instaladas, tudo isso convertia o período em um dos mais cruéis para a grande massa que sempre viveu do suor do rosto (FALBEL, 1978, p. 29).

O Romantismo, mesmo dentro de sua heterogeneidade de vertentes e significados, traçou para si, fator que o definiu como movimento artístico e visão de mundo, a tarefa de crítico dos aspectos negativos do capitalismo industrial e do conjunto de valores sociais e morais defendidos pela burguesia. ${ }^{3} \mathrm{E}$ é com esse embasamento crítico central que o movimento romântico irá se firmar como estética de oposição de uma modernidade industrial burguesa, defensora da onipotência do dinheiro e da competitividade produtiva.

Segundo Hauser (1995, p. 554), o surgimento de uma modernidade industrial burguesa provocou na sensibilidade romântica um "protesto contra a mecanização" e uma crítica da "despersonalização da vida relacionada com uma economia deixada à rédea larga", aliada a uma "profunda melancolia que se apodera das almas" e o "anseio de um mundo longínquo e desconhecido, distante do presente".

Dentre os autores analisados, que se reportaram ao Romantismo como fenômeno crítico da modernidade, entendida, no presente estudo, como modelo civilizatório alicerçado no avanço industrial regulador das esferas sociais, políticas, econômicas e culturais, Lowy e Sayre aparentam ser os que mais veementemente afirmam essa ideia.

Tanto para Lowy quanto para Sayre, o estudo sobre o Romantismo deve se concentrar na questão da visão de mundo romântica, vista como elemento comum entre as várias formas que o movimento romântico se constituiu. Desse modo, a visão de mundo romântica passa a ser o ponto nevrálgico para uma compreensão mais profunda do arcabouço mental de um particular setor social europeu enquadrado por um tumultuoso período histórico que vai do final do século XVIII até a metade do século XIX.

\footnotetext{
3 No presente trabalho, o conceito de "burguesia" é entendido como o conjunto de homens, que representados como classe, defendiam um posicionamento diante do mundo, em absoluta correspondência com o desenvolvimento industrial da sociedade capitalista. A ordenação das relações econômicas, sociais e políticas como visão de mundo burguesa estabelecia "[...] o nivelamento dos valores morais à regra benthamiana do maior interesse e da melhor utilidade, a marginalização social de toda atividade improdutiva, o princípio fiduciário da moralidade burguesa, as relações possessivas da moral doméstica e do casamento, a separação entre as esferas sexual e sentimental do amor, [...]" (NUNES, 1978. p 55).
} 
A visão de mundo romântica, chamada por Lowy e Sayre de Weltanschuung, ou estrutura mental coletiva, é baseada numa concepção de mundo que toma o passado como referência, mostrando o caráter essencialmente histórico do Romantismo, de valores e questões éticas, mas sendo, muitas vezes, um período que de fato nunca existiu, mas interpretado e recriado a partir de um hipotético modelo social, como utopia romântica. ${ }^{4}$

Desse modo, o dado unificador das muitas variantes do Romantismo se encontrava, justamente, na visão de mundo passadista julgadora da modernidade, ideia carregada de um forte viés nostálgico, mas também anunciadora de um desejo de mudança e superação das relações sociais, dadas pela ordem industrial.

A nostalgia de um paraíso perdido é acompanhada, quase sempre, por uma busca do que foi perdido [...]. Esse impulso pode se manifestar pelo surgimento do sobrenatural, do fantástico, do onírico, ou então, em determinadas obras de arte, pela tonalidade do 'sublime'. No entanto, em outro sentido, toda criação artística romântica é uma projeção utópica - um mundo de beleza - criada pela imaginação no momento em que é concebida (LOWY; SAYRE, 1995, p. 42).

Assim sendo, para Lowy e Sayre (1995, p. 33), “[...] o Romantismo é, por essência, uma reação contra o modo de vida da sociedade capitalista [...], portanto, (surge) na segunda metade do século XVIII e ainda não desapareceu".

O movimento romântico, inserido e analisado como fenômeno histórico, advindo de mudanças estruturais paradigmáticas engendradas pela modernidade capitalista, é visto para Lowy e Sayre, e, da mesma forma, para outros autores e estudiosos, como tendo uma gênese e um término como escola literária e artística. Mas, para os autores em questão, a visão de mundo romântica, como esteve interligada com as características do fenômeno de produção industrial e da modernidade burguesa, não esgotou sua crítica e nem desapareceu como conjunto de valores. Do mesmo modo que a industrialização e suas consequências culturais continuam como processo histórico, a visão de mundo romântica se diluiu em outras

\footnotetext{
4 Sobre as utopias românticas, podemos dizer ainda: "Toda a sua política (tendo como ponto de referência as motivações românticas), em seu amplo significado, passou a traduzir-se num constante e reiterado apelo ao ideal; as representações e as imagens, e as ideias delas advindas, foram consideradas forças incomensuráveis de transformação completa da história e da sociedade" (SALIBA, 2003, p. 36).
} 
criações artísticas e permaneceu como ponto de visualizações utópicas e caminhos alternativos para a existência humana.

Como já tinham sido verificadas por Max Weber, as principais características da modernidade - o espírito de cálculo ('Rechnenhaftigkeit'), o desencantamento do mundo ('Entzauberung der Welt'), a racionalização instrumental ('Zweckrationalitat') a dominação burocrática - são inseparáveis do advento do 'espírito do capitalismo' (LOWY; SAYRE, 1995, p. 35).

\section{1 "It's a wonderful life" ("A felicidade não se compra") de Frank Capra e a "visão de mundo" romântica}

Podemos dizer que o cineasta americano Frank Capra, filho de uma pobre família de imigrantes italianos, simboliza a própria ideia de self made man, ou seja, do homem autônomo, "que se faz por si mesmo". O self made man é aquele que vence com bravura as adversidades da vida, firmando-se como modelo e síntese da nação norte-americana, encarada como terra da liberdade e das oportunidades.

Como produtor e diretor de filmes, Capra assumiu uma posição de destaque no governo do presidente Franklin Delano Roosevelt, guiando sua produção fílmica como instrumento de propaganda política. Para isso, projetou temas mais complexos e voltados aos problemas sociais no cinema norte-americano, em atitude que ia contra ao posicionamento de Hollywood, diante dos problemas gerados pela Grande Depressão.

\footnotetext{
Em 1932, a crise entrou pelos estúdios cinematográficos adentro, propagando-se na realidade e na ficção, o que levou o cineasta Frank Capra a constatar dois fatos evidentes: se é a população deprimida que começa a encher cada vez menos as salas de cinema, então os filmes, dada a crise na produção motivada pela queda das receitas, deve dirigir-se a seu público concreto - o escapismo (filmes do gênero musical) já não motivava as pessoas cansadas de sonhar sozinhas, sem que ninguém as transformasse em heróis cinematográficos (PEREIRA, 2006, p.75).
}

Cumprindo as palavras de ordem da política do New Deal, da Era Roosevelt, Frank Capra dirigiu filmes como "O galante Mr. Deeds" (1936) e "A mulher faz o homem" (1939), que tinham como personagens principais homens comuns, envolvidos com o trabalho e tocados pelos problemas sociais.

Os personagens centrais dos filmes de Capra, desse período, encarnam o modelo de "homem novo", trabalhador, honesto, comprometido com os valores da comunidade e destemido, ou seja, é a reafirmação do modelo de self made man.

Cad. de Pesq. Interdisc. em Ci-s. Hum-s., Florianópolis, Santa Catarina, ISSN 1984-8951 v.15, n.106, p. 48-58 - jan./jun. 2014 
Mas, Capra, mesmo sendo um cineasta em sintonia com o discurso político oficial do New Deal e um membro do panteão de Hollywood, pode ser também incluído dentro de outra linha crítica da realidade norte-americana, uma histórica e outra contemporânea.

De acordo com o pesquisador Pereira (2006, p. 74), o romance "As Vinhas da Ira", de John Steinbeck, do ano de 1939, figura-se como a obra mais expressiva sobre os efeitos da Grande Depressão econômica, dotada de uma forte denúncia social e de uma intensa sensibilidade. Numa análise mais cuidadosa, podemos traçar uma relação de reciprocidade entre algumas ideias do livro de Steinbeck com alguns temas do cinema de Capra, a partir deste trecho:

\begin{abstract}
A obra de Steinbeck une realismo a um romantismo primitivo, que encontra virtudes nos pobres agricultores que vivem próximos à terra. Sua ficção demonstra a vulnerabilidade dessas pessoas, que podem ser expulsas pelas secas e são as primeiras a sofrer em épocas de instabilidade política e depressão econômica. O pano de fundo do romance, marcado pela piedade ao sofrimento humano alheio, e pelo protesto, a revolta perante as injustiças do mundo, faz com que Vinhas da Ira sejam não somente um sinônimo da grande depressão econômica da década de 1930, mas também o testemunho histórico de uma época (PEREIRA, 2006, p. 74).
\end{abstract}

Não podemos negar que a crítica social de John Steinbeck é mais ácida que os filmes de Frank Capra, referentes ao período da Grande Depressão. Mas, em ambos, ressoa a denúncia das injustiças sociais causadas por um modelo políticoeconômico capitalista, que transforma os homens em seres guiados pela vontade do lucro, a qualquer preço, e despossuídos de qualquer sensibilidade, diante dos sofrimentos do próximo.

Além da denúncia social em ambos, é marcante a presença de indivíduos dotados de um libertário sentimento de comunhão e entrega, agindo de formas totalmente opostas àquelas esperadas e propostas por uma visão de mundo egoísta e competitiva.

O milionário Deeds, no filme de Capra, que ajuda os pobres de maneira desinteressada, ou as mulheres da família Joad, do romance de Steinbeck, que ofertam a um desconhecido moribundo o próprio alimento da vida, revelam uma nova forma de conceber a existência alicerçada, numa proposta de renovação da sensibilidade humana e da ordem política e econômica. 
A visão de mundo romântica, como ponto crítico da modernidade capitalista, esteve presente na intelectualidade norte-americana a partir de diversas heranças literárias, como na literatura transcendentalista de Ralph Waldo Emerson, Henry David Thoreau e Walt Whitman, ${ }^{5}$ nos contos de Edgard Allan Poe e no realismo "poético" de John Steinbeck. Heranças essas que foram captadas de forma direta e indireta pela produção fílmica de Capra.

No filme "A Felicidade não se Compra" (1947), como representante da filmografia de Capra, podemos notar uma implícita crítica aos males causados pela modernidade capitalista que dialoga com uma visão de mundo romântica, herdeira de temas trabalhados por alguns autores da intelectualidade norte-americana e da observação da realidade social corroída pela Depressão.

O filme, de um modo geral, conta a história de Bailey, homem bom e querido por todos, e que devido a um incidente (perda de um importante cheque) e a outros problemas financeiros, resolve cometer suicídio, mas que, no momento fatídico, acaba recebendo a ajuda de um anjo, que o revela o quanto a sua vida é importante e maravilhosa.

O personagem Bailey, interpretado por James Stewart, vive na cidadezinha de Bedford Falls, um tipo de cidade ideal que só encontramos em livros e filmes, onde todos os habitantes se conhecem e uma atmosfera de companheirismo pode ser sentida, mas que, desde criança, Bailey sonha em deixar.

Numa caracterização de Bailey não podemos deixar de citar o seu forte desejo de viajar, de conhecer lugares exóticos e de viver novas experiências, impossíveis de conceber em lugares tão pacatos e previsíveis como Bedford Falls. Com esse personagem, Capra nos apresenta um modelo de homem sonhador e

\footnotetext{
${ }^{5}$ Sobre a relação entre a visão de mundo romântica e o Transcendentalismo, podemos citar a crítica que esse grupo fazia ao desenfreado expansionismo territorial promovido pelo governo norteamericano. "[...] é preciso lembrar a existência de uma forte oposição ao projeto de anexação territorial por parte de algumas organizações norte-americanas. Devemos destacar o movimento conhecido como Transcendentalismo, do qual faziam parte homens influentes da Nova Inglaterra, como Emerson e Thoreau. Para os membros desse grupo, a 'natureza selvagem' era o lugar da revelação, onde o homem era capaz de encontrar a 'centelha divina', e por isso, deveria ser preservada. Inspirados pelo romantismo europeu, os transcendentalistas denunciavam o expansionismo, posicionando-se frontalmente contra a guerra com o México e a favor da abolição dos escravos. Sobre a anexação de territórios, Emerson, acurado observador da sua época, afirmava que o ímpeto por anexação era tal que o norte-americano estava perdendo os seus princípios simples numa busca desenfreada por propriedades e lucros" (JUNQUEIRA, 2001. p. 54).
} 
romântico, aquele que simbolizaria para milhares e milhares de espectadores os valores de um "novo homem americano".

Como sonhador e romântico, Bailey não titubeia em se jogar num lago gelado para salvar seu irmão Harry; em arriscar seu primeiro emprego para salvar o atormentado farmacêutico Mr. Gower, que sofre com a morte do filho; em ir para a prisão; e em colocar em situação de falência a cooperativa que dirige, para atender os anseios dos mais pobres em ter uma casa própria. Bailey é um self made man, um alguém que não foi afetado pela competição e individualismo da modernidade capitalista, um homem disposto a entregar a realização de seus sonhos e suas riquezas em prol da felicidade do próximo.

Bailey, como nenhum outro, encarna a ideia do "Adão americano", um ser puro e inocente, ${ }^{6}$ dotado de energia para construir o seu futuro e, ao mesmo tempo, da sua comunidade. O personagem representa o companheirismo do americano em seu estado natural, daquele que não foi tocado pela ganância e cobiça da modernidade capitalista, um indivíduo que ajuda, de forma desinteressada, os membros de sua comunidade, porque se vê igualmente, em relação aos demais, e incapaz de julgar os outros por suas posses ou posições sociais. Um verdadeiro símbolo do que Frank Capra acreditava ser a essência do ideal democrático norteamericano.

Outro personagem central de "A Felicidade não se Compra" é o rico Henry F. Potter (Lionel Barrymore), inimigo natural de Bailey, pelo fato de caracterizar o contrário de tudo que Bailey representa. Mr. Potter é avarento, ganancioso (quer controlar tudo e todos em Bedford Falls), invejoso, individualista e mau, ou seja, representa os ideais e a visão de mundo do homem capitalista por excelência, algo que o filme pretende combater.

Desde criança, Bailey enfrenta difíceis decisões e sempre escolhe o lado mais vantajoso para os outros. Abandona duas vezes o sonho de viajar, primeiro em prol

\footnotetext{
6 "Acreditava-se que surgia nos Estados Unidos um 'novo homem' com características notáveis, um ser único que, a partir da Independência, havia não só rompido com a Inglaterra, mas com o passado. Elaborou-se um versão de que o norte-americano era um ser humano completamente diferente do europeu, pois havia realizado não só a separação política da Inglaterra, mas uma ruptura com a História. Completamente desvinculado do passado, era tido como o Adão norte-americano; 'emancipado da História', era inocente e espontâneo, sem pecados ou culpas [...]. O Adão americano tinha apenas o futuro pela frente. Ao novo homem norte-americano, tido como dotado de energia excepcional, cabia uma tarefa espetacular: construir o mundo a partir do zero" (JUNQUEIRA, 2001. p. 49).
} 
do bem-estar de seu irmão Harry, fato que faz com que Bailey assuma com força total a cooperativa do pai, emprego desprezado por ele, para que Harry pudesse abraçar um ótimo emprego oferecido por seu sogro. Segundo, e de forma definitiva, Bailey deixa sua viagem de lua-de-mel de lado para que os membros da sua cooperativa tivessem dinheiro para enfrentar a grande crise econômica.

Outro tema importante do filme é o amor entre Bailey e Hatch, amor intenso, pleno e resistente ao tempo. Ao longo do filme, a personagem Mary recusa pretendentes mais ricos e bem situados socialmente, como o ambicioso industrial Sam Wainwright, para ficar com George, não se importando com as possíveis dificuldades financeiras do futuro.

O casal Bailey e Hatch, vivida pela bela atriz Donna Reed, também pode ser entendido como elemento de crítica à modernidade capitalista, na sua idealidade e perfeição. O casamento de ambos só não é plenamente feliz por causa dos problemas gerados pelo aspecto financeiro e pelas tramoias de Mr. Potter para destruir a cooperativa de Bailey, que a cada dia constrói mais casas para os antigos inquilinos miseráveis de Mr. Potter.

Dentro de uma bem arquitetada estrutura melodramática, a intensidade do amor de Bailey e Hatch é realçada pela presença do "leitmotiv", representado na imagem de Bailey laçando a Lua, na música "Buffalo Calls", de Arthur Black e na velha casa da cidade, vislumbrada no primeiro passeio a sós do casal e futura moradia de ambos.

Mas, como já foi apontado, nem mesmo a presença de um amor tão intenso, de filhos adoráveis e de fiéis amigos foram suficientes para aplacar a decisão final de Bailey de cometer suicídio, devido à falta de recursos financeiros para pagar o valor impresso de um cheque perdido (que foi encontrado por Mr. Potter e maldosamente escondido).

No momento em que ia consumar o ato, um anjo é enviado dos céus para ajudar Bailey. Esse anjo é Clarence, um antigo sapateiro que avidamente ansiava por ganhar suas asas celestiais. A estratégia utilizada por Clarence para que Bailey desistisse de cometer suicídio foi lhe revelar uma hipotética Bedford Falls, uma cidade em que a figura de Bailey jamais existiu.

Juntamente com o anjo, Bailey se depara com uma cidade completamente diferente daquela que ele havia conhecido. O próprio nome dessa cidade lhe era 
inteiramente desconhecido, "Potter's Town". Com o desenrolar de sua jornada, Bailey nota que toda a cidade, administrada por Henry F. Potter, tinha perdido toda sua atmosfera comunitária e amistosa, sendo substituída por habitantes grosseiros e desprovidos de compaixão, e por boates e salões de jogos, ou seja, havia deixado de ser uma representação idílica para se tornar a representação dos valores capitalistas pregados por Mr. Potter.

Numa constante descrença e desapontamento, Bailey descobre que seu irmão Harry nunca conseguiu ser um herói de guerra, porque havia morrido num lago congelado. Sua mãe tinha se tornado uma senhora triste e amargurada, todas as pessoas que tinham conseguido uma casa própria por intermédio dele, continuavam pagando aluguel para Potter, e sua amada Mary era infeliz por nunca ter encontrado o amor.

Desesperado e perseguido pela polícia, Bailey pede a sua vida de volta e consegue que seu pedido seja aceito. Tudo volta ao que era antes: as pétalas de rosa da sua filha Zuzu no seu bolso, o carro batido na árvore, o machucado na boca e as dívidas. Mas, Bailey havia mudado, finalmente compreendera o significado das palavras do anjo Clarence: "é incrível como nossa vida toca a vida dos outros".

Quando Bailey retorna a sua casa, imediatamente restabelece a paz com sua família e recebe a visita de convidados inesperados para o Natal. Em grande número, os habitantes da cidade entram na sua velha casa dispostos a ajudar Bailey, o símbolo da comunhão entre os homens e o "homem mais rico de Bedford Falls".

Com o filme "A Felicidade não se Compra", o cineasta Frank Capra concebe um perfeito instrumento de propaganda política para os interesses da Era Roosevelt. Capta os valores do "novo homem" americano, nascido na luta contra a Depressão, redefine os valores do american way of life, e contribui com a propagação de ideais nacionalistas. Mas, indiretamente, Capra traça uma crítica aos valores da modernidade capitalista, utilizando-se de instrumentos voltados a uma particular visão de mundo romântica, como a ideia do "Adão americano" e do sentimento de comunidade, inexistentes em tempos tão individualistas e competitivos. O filme de Capra pertence a seu tempo, mas não podemos negar o seu papel de libelo da generosidade humana e do sonho filantrópico presentes no imaginário romântico. 


\section{Referências}

CAPRA, F. A Felicidade não se Compra. Título original: It's a Wonderful Life. 1947. Roteiro e Direção de Frank Capra. Distribuído pela Paramount.

FALBEL, N. Os fundamentos históricos do Romantismo. In: GUINSBURG, J. (Org.). O Romantismo. São Paulo: Perspectiva, 1978. p. 23-50.

JUNQUEIRA, M. A. Estados Unidos: a consolidação da nação. São Paulo: Contexto, 2001.

HAUSER, A. História Social da Arte e da Literatura. São Paulo: Martins Fontes, 1995.

LOWY, M.; SAYRE, R. Revolta e Melancolia - O romantismo na contramão da modernidade. Petrópolis, Rio de Janeiro: Vozes, 1995.

NUNES, B. A Visão Romântica. In: GUINSBURG, J. (Org.). O Romantismo. São Paulo: Perspectiva, 1978. p. 51-74.

PEREIRA, W. P. 24 de Outubro de 1929: A Quebra da Bolsa de Nova York e a Grande Depressão. São Paulo: Companhia Editora Nacional, 2006.

SALIBA, E. As utopias românticas. São Paulo: Estação Liberdade, 2003.

Artigo:

Recebido em: 29/05/2013

Aceito em: 04/07/2014 